\title{
Toda la renta se desvanece en el aire El caso de las Agencias Regionales de Desarrollo Productivo
}

\author{
Francisco Durán
}

Universidad de Aysén, Chile

\section{Resumen}

El proyecto modernizador aplicado en Chile durante las últimas décadas ha consolidado una estructura productiva preponderantemente rentista, dependiente de los ciclos del precio de las materias primas y de mercados altamente concentrados. A partir del proceso de descentralización en curso, que modifica la interrelación entre los actores territoriales más preponderantes, esta investigación identifica las principales barreras que impiden o retrasan la transformación productiva a nivel territorial, especialmente al considerar las nuevas facetas de la descentralización en el ámbito político-institucional. Para esto, se consideran los casos de las Agencias Regionales de Desarrollo Productivo de las regiones de Valparaíso y Coquimbo. En virtud del análisis realizado, se evidencia que los factores económicos y sociales son fundamentales para entender el éxito o fracaso de una política de desarrollo productivo a nivel territorial, siendo el factor institucional insuficiente para explicar esto de forma integral. Se concluye que es esencial el proceso que fortalece las capacidades endógenas de los territorios, puesto que son el sustento de la nueva fase de la descentralización.

Palabras clave: Desarrollo territorial, descentralización, proyecto modernizador, cohesión social, política industrial.

\section{All the Rent Fades into the Air. The Case of the Regional Productive Development Agencies}

\begin{abstract}
The modernizing project implemented in Chile in recent decades has established a production structure predominantly rentier, that depends on the cycles of the raw materials price and markets highly concentrated. From the ongoing decentralization process, which modifies the interaction between the main regional players, this research identifies the main barriers which prevent or delay the productive transformation at local level, especially considering the new facets of decentralization in the politicalinstitutional field. For this, the study considers the cases of the Regional Development Agencies in the regions of Valparaiso and Coquimbo. The analysis shows that economic and social factors are key to understanding the success or failure of a production development policy at local level, and the institutional factor is insufficient to explain this holistically. We conclude that the process that strengthens the endogenous capacities of the territories is essential, since they are the basis of the new phase of decentralization.
\end{abstract}

Keywords: Territorial development, decentralization, modernizing project, social cohesion industrial policy. 


\section{Políticas de desarrollo en Chile}

$$
\begin{array}{r}
\text { "Todo lo sólido se desvanece en el aire; } \\
\text { todo lo sagrado es profanado, } \\
\text { y los hombres, al fin, } \\
\text { se ven forzados a considerar serenamente } \\
\text { sus condiciones de existencia y } \\
\text { sus relaciones reciprocas" } \\
\text { Karl Marx }
\end{array}
$$

"El capitalismo es incapaz de inventar un futuro que no reproduzca ritualmente su presente"

Terry Eagleton

La llegada del siglo XXI condujo a una intensificación del comercio internacional en el marco de un nuevo auge de la globalización, apoyada esta vez con nuevas tecnologías y renovadas políticas de integración regional y mundial. A su vez, se ha generado un desplazamiento de las fuerzas económicas mundiales que muestran un paulatino desacoplamiento económico, a la sazón de la aparición y consolidación de un nuevo gigante económico: China. Este fenómeno ha reconfigurado el mapa económico mundial y, por supuesto, ha impactado en los países de América Latina, introduciendo nuevos desafíos en términos sociopolíticos y económicos que presionan a los distintos gobiernos del continente.

El principal desafío que emana de esta situación, dice relación con el tipo de crecimiento que predomina en la región, en el marco de una excesiva dependencia en los recursos naturales. Esto, sin embargo, ha tenido una doble cara: por una parte, la renta generada por la explotación de estos recursos ha financiado la instalación de sistemas de protección social, mejorando el déficit fiscal, provisionando ingresos que han aumentado las arcas fiscales como base para las políticas contra cíclicas; pero, por otra parte, la variabilidad de los precios de las materias primas ha generado incertidumbre respecto de la capacidad de apalancar recursos y distribuirlos adecuadamente.

En primer lugar, afecta a la diversificación productiva, en la medida que las inversiones se abocan casi exclusivamente a los recursos naturales, en desmedro de los otros sectores productivos, como ha quedado en evidencia al observar el comportamiento de la inversión extranjera directa (IED). Esto es especialmente delicado, por cuanto la explotación de recursos no renovables se realiza sobre la base de una escueta proporción de la fuerza laboral, que en muchos países no alcanza al dos por ciento del total. En segundo lugar, incentiva comportamientos rentistas, es decir, la proliferación de empresas que, dada la renta que reciben, no se comprometen con la innovación y la agregación de valor a la economía y la sociedad, así como tampoco al mejoramiento continuo de las condiciones laborales. Esto último ha impactado en la definición de las políticas macroeconómicas y comerciales en la medida que han buscado facilitar la explotación de los recursos naturales, desprotegiendo a la industria nacional (CEPAL, 2014).

Esto se ha reflejado en distintos resultados, que suelen representarse en los esfuerzos que realizan los países para avanzar hacia una mayor diversificación productiva y exportadora. Al respecto, es clave constatar que la participación en las exportaciones mundiales de los países de América Latina y la capacidad de introducir intensidad tecnológica en la composición de las exportaciones de bienes, ha disminuido drásticamente. Así, en la última década se han "reprimarizado" las exportaciones, principalmente por el efecto de China, que ha demandado una gran cantidad de materias primas para su crecimiento económico, pero también, y no menos importante, por la creciente "financiarización" de los commodities a nivel mundial, que ha logrado mantener elevados los precios cuando la demanda física de estos recursos disminuye. Estos procesos han implicado, a su vez, una mayor concentración de las empresas exportadoras en cada país, lo que por cierto tiene consecuencias en la distribución de los ingresos, que se mantiene profundamente desiguales en la región.

La estructura económica de Chile, se caracteriza por dos grandes elementos: por una parte, por la explotación de recursos naturales, circunscrita a la extracción y transacción de materias primas con escaso valor agregado; y, por otra parte, por la predominancia de procesos de concentración económica, en la medida en que hay abusos de poder dominante, colusiones y fusiones en el marco de prácticas monopólicas u oligopólicas, las que finalmente operan bajo la misma lógica rentista tradicional. Planteado de esta forma, es claro entonces que la matriz productiva queda restringida por una hegemonía rentista que se expresa a través de diferentes vías: institucionales, económica y culturales.

Una consecuencia directa de esta situación, han sido los altos niveles de desigualdad que aún padece el país, que no solo se asocian a la desigual distribución de los ingresos y de capital cultural, sino también a la desigualdad que se expresa en el rezago de algunos territorios respecto de otros. A ello, se suman los procesos de concentración económica, la masificación de empleos precarios y un progresivo proceso de desindustrialización, pero también, y no menos importante, una creciente pérdida de sentido de pertenencia, de ciudadanía y confianza entre los actores sociales, que finalmente socavan las bases de legitimidad del proyecto político de sociedad. Todas estas problemáticas muestran el agotamiento de la estrategia de desarrollo llevada hasta ahora 
y la necesidad de su reemplazo ${ }^{1}$.

Para responder a esta problemática, es que en el último tiempo se han introducido reformas, políticas y programas orientados a redefinir la institucionalidad pública, reordenar la asignación de recursos y promover la articulación de los actores regionales del desarrollo en el marco de las alianzas público-privadas. Todo esto, por cierto, enmarcado en un proceso de descentralización que ha buscado la transferencia de competencias hacia las propias regiones para una mayor autonomía política, administrativa y fiscal.

En ese marco, es particularmente importante la implementación del Sistema Regional de Planificación (SRP), en cuya base se encuentran las estrategias regionales de desarrollo, las políticas regionales de ordenamiento territorial y los proyectos de inversión. En paralelo, se encuentran las políticas de desarrollo productivo ¿algunas veces denominada política industrial?, las que se han basado principalmente en el principio de neutralidad y horizontalidad, es decir, fomentadas para corregir fallas del mercado sin discriminar entre actividades económicas.

En el caso de la articulación de actores regionales a través de instancias público-privada, parece necesario profundizar en los fundamentos que incitan la búsqueda de esta alternativa, por cuanto no hay claridad respecto de las consecuencias sobre el desarrollo de largo plazo que tiene una política de este tipo. Si bien es una experiencia que se ha aplicado en varios países, las evaluaciones realizadas (CEPAL, 2006; CEPAL, 2010; Moguillansky, 2012; Devlin y Moguillansky, 2010;Moguillansky, 2010) muestran resultados dispares, incluso dentro de un mismo país.

En esta tentativa, este artículo analiza el desafío del desarrollo productivo territorial desde una triple perspectiva: económica, sociológica y políticoinstitucional, con un desarrollo concéntrico en torno al problema, es decir, que se asoma desde distintos ángulos y niveles, de forma directa o indirecta, en cada momento, para dar cuenta de los elementos estructurantes que condicionan la contingencia. El entrecruzamiento de este eje estructural con las particularidades del fenómeno, en cuanto temática territorializada, permite realizar un análisis integral y holístico orientado a comprender, de forma correlativa, las derivaciones que impone el fenómeno en cuestión. Por lo tanto, se busca responder a la siguiente pregunta de investigación: ¿cuáles son las barreras que impiden la transformación productiva

\footnotetext{
${ }^{1}$ Todo esto se agudiza con el desplome del súper ciclo de precios del cobre, actualmente en curso, y que se repite cada cierto tiempo.
}

a nivel territorial en el marco de las políticas de desarrollo productivo y, en particular, a través de las alianzas público-privadas regionales?

Para identificar estas barreras de forma precisa y proponer algunas salidas, se utilizan dos enfoques teóricos: por una parte, (i) la economía clásica y la teoría del desarrollo, para comprender las consecuencias de la hegemonía rentista sobre la estructura económica en la perspectiva de la transformación productiva; y, por otra parte, (ii) la sociología , para comprender los obstáculos que padece un desarrollo inclusivo y la transformación productiva en el ámbito social e institucional, especialmente teniendo en consideración el desafío de construir una agenda público-privada colaborativa a nivel territorial.

El enfoque conceptual propuesto es contrastado con las voces de los actores regionales de modo de elaborar un análisis completo de dichas barreras. Para ello se ha seleccionado el caso de las Agencias Regionales de Desarrollo Productivo (ARDP), en el entendido de que estos organismos expresan el desafío de la descentralización del desarrollo productivo. En ese contexto, por lo tanto, se entienden estos organismos no sólo como objeto de las políticas públicas sino también como sujetos de las mismas, esto es, con capacidad de orientarlas y dinamizarlas.

Respecto de las entrevistas, estas han sido analizadas recogiendo las afirmaciones de expertos y profesionales en función de las siguientes dimensiones, obtenidas del análisis teórico y conceptual: económica, social y político-institucional ${ }^{2}$; se ha puesto especial atención al movimiento que va desde lo general a lo particular, y viceversa, de modo de construir un relato que conecte las problemáticas identificadas en diferentes niveles de abstracción. Como señala Ibáñez (2003), se trata de una interpretación que asume tres niveles de análisis: uno macro, otro intermedio y uno micro -que el autor denomina los niveles nuclear, autónomo y sýnnomo, respectivamente-, a fin de captar la realidad que se va reabsorbiendo en producción y consumo de sentidos. Es importante señalar que el nivel micro es el momento de la totalización: es aquí donde se refleja la situación macro, esto es, el fenómeno como respuesta a un proceso histórico y social. Por lo tanto,

\footnotetext{
${ }^{2} \mathrm{~A}$ partir de cada una de estas dimensiones se elaboraron las respectivas variables a fin de delimitar contenidos específicos de interés. Así, para la dimensión económica se incluyeron las siguientes variables: "estructura productiva regional"; "empresas regionales"; y "sistema de educación superior". Para la dimensión social las siguientes variables: "cohesión social"; y "cohesión territorial". Para la dimensión político-institucional: "liderazgo de la institucionalidad pública"; "articulación público-privada"; y "estrategias y políticas públicas"
} 
se utiliza un análisis de contenido que enfatiza en el aspecto analítico de las fuentes textuales, para luego, en las ocasiones requeridas, transitar hacia el nivel interpretativo - que es donde se revela el marco teórico propiamente tal (Navarro y Díaz, 1995).

\section{Transformación productiva y desarro- llo territorial}

Los desafíos que implica comprender el desarrollo desde una perspectiva holística, supone profundizar en aquellos factores que facilitan u obstaculizan dicho cambio, y para ello resulta fundamental referirse a las salidas teóricas que buscan equilibrar la relación entre agencia-estructura (Archer, 1996; 1998; 2009) en el contexto de la desmodernización (Touraine, 1999). Es decir, es primordial entender las consecuencias que emanan de la tensión existente entre individualidad y comunidad en el contexto del mejoramiento de la cohesión social para el desarrollo (CEPAL, 2007). En ese sentido, es necesario interrogarse acerca de las condiciones sociales bajo las cuales es posible pensar y llevar a cabo cambios estructurales: de esta forma, ¿es la ausencia o presencia de la cohesión social un factor primordial para el cambio estructural y la aplicación de una nueva estrategia de desarrollo? ¿Cómo es el tratamiento que se le está dando a este concepto para estos propósitos? ¿Cómo debiera relevarse en el horizonte de una nueva estrategia?

En este punto también es importante abordar la dimensión territorial de la cohesión social y de la transformación productiva, en la medida que el territorio no es un factor circunstancial del análisis del crecimiento económico, sino que es un elemento explicativo esencial del proceso de desarrollo (Moncayo, 2001). Es decir, la relación entre desarrollo y territorio no debe circunscribirse únicamente en su aspecto espacial y funcional, sino también debe considerar de manera fundamental la sinergia entre territorios en el marco de una estrategia de desarrollo mayor. En este caso, el concepto de desarrollo de capacidades (Sen, 2000; Delamaza, 2013) y la perspectiva del desarrollo como una propiedad emergente (Boisier, 2007) permiten describir y analizar las dificultades que algunos territorios tienen para avanzar hacia un cambio estructural a través de una política industrial. Esto es importante porque en principio se entiende que en territorios con baja cohesión social (o capital social en este caso) es más difícil introducir cambios sustanciales (CEPAL, 2003; Rodríguez y Román, 2005; OCDE, 2009; SUBDERE, 2011).

En ese sentido, el concepto de desarrollo, entendido como un proceso de construcción de capaci- dades sociales; esto es, productivas, tecnológicas e institucionales; en un contexto de incertidumbre y desequilibrio (Katz, 2008), permite comprender de forma integral los avances y retrocesos de los distintos países.

\section{El dilema de la producción de valor}

Toda economía que se basa en la explotación de los recursos naturales carece de procesos productivos que agreguen valor a la economía. Esto porque, siguiendo a Smith, Ricardo y Marx, la única fuente de valor es el trabajo humano destinado al proceso productivo de bienes y servicios que se venden en el mercado. Por lo tanto, la única forma de que el valor varíe, es actuando sobre el trabajo humano, es decir, situando al trabajador en contextos de mayor productividad, la que sólo se logra aumentando la intensidad del trabajo, o bien incorporando trabajadores más calificados a los procesos productivos. Los cambios tecnológicos no incrementan, sino por el contrario, reducen el tiempo socialmente necesario para producir una mercancía, y por lo tanto su valor. Dicho efecto se esfuma cuando la innovación se generaliza y bajan los costos promedios de toda la industria (Riesco, 2012).

Por supuesto, al sostener esto, hay que explicar la diferencia entre valor y precio. Al señalar que la fuente del valor es el trabajo humano incorporado a los procesos de bienes y servicios que se venden en el mercado ocurre una situación que puede ser paradójica: puede suceder que una mercancía no se venda por el valor del trabajo necesario para producirlo, sino que adquiera un valor distinto; en este caso, el precio que adquiere una mercancía puede ser diferente del valor, y esto se explica porque los precios son locales y temporales y sensibles al dinamismo de los mercados, mientras el valor es un fenómeno histórico y global que depende de transformaciones sociales y culturales. Es decir, si bien la suma de todos los precios es igual a la suma de todos los valores de las mercancías que logran venderse en el mercado, y que se refleja de forma precisa en el Producto Interno Bruto mundial, los precios y valores individuales no logran esta convergencia. El motivo es la existencia de importantes transferencias de valor, vía precios, de unas mercancías a otras, de unas industrias hacia otras y de unos productores a otros (Riesco, 014a). Por lo tanto, la forma de explicar las ganancias -incluyendo las ganancias de capital y la renta- de los distintos sectores productivos, así como también las diferencias en los rendimientos de capital y el crecimiento de la economía, es a partir de las cuatro transferencias de valor que identificaron los economistas clásicos y que resultan fundamentales para comprender los 
desafíos que conlleva el tránsito hacia economías basadas en el conocimiento y la innovación.

La renta constituye una de las más importantes transferencias de valor, desde mercancías que se producen en una situación de competencia y, por lo mismo, cuyos precios se reducen constantemente por debajo del valor incorporado por el trabajo humano, hacia mercancías basadas en recursos escasos, cuyos precios varían de forma permanente pero siempre por sobre los costos de producción, los que incluyen la ganancia capitalista media. De esta forma, las mercancías de estos últimos, adquieren, a pesar de que usualmente agregan muy poco valor, un sobreprecio en virtud de que son insumos fundamentales para los primeros, de los cuales obtienen el valor transferido correspondiente al intercambio de mercado (Acquatella et al., 2013; Riesco, 014a; Riesco, 014b; del Litio, 2015).

Así las cosas, los precios se conforman a partir de los costos de producción, los que incluyen los salarios, el pago a proveedores y la ganancia media de la rama productiva correspondiente. Sin embargo, las características de las distintas ramas productivas, así como sus lógicas internas, conducen a diferentes transferencias de valor que hacen variar los precios y, por lo tanto, las ganancias asociadas (Riesco, 014a).

\section{El devenir de una modernización pro- blemática}

La modernidad ha impuesto la necesidad de resignificar la relación entre economía y sociedad, siendo esta última un elemento cada vez más importante para explicar los determinantes del crecimiento. Si en un inicio se hizo hincapié en la acumulación de capital, el cambio tecnológico, la educación, capacitación y capital humano, los incentivos para la innovación y la distribución del ingreso; últimamente, el foco ha estado puesto sobre las relaciones de confianza, como uno de los principales factores que permite mejorar el crecimiento económico, particularmente cuando se invoca a la innovación y el emprendimiento (Peña, 2008).

Por lo tanto, en la medida que ha ido aumentando la complejidad, interdependencia, riesgos, incertidumbre y los costos de transacción en los procesos productivos, se ha requerido mirar los aspectos menos tangibles y visibles de los fenómenos económicos. Esto, por supuesto, se ha instalado con fuerza sin la necesaria reflexión acerca de la matriz sociopolítica sobre la cual descansa (Garretón, 2004) y la subjetividad que la constituye (Lechner, 2002), por lo tanto, deviene problemática cuando requiere promover estos aspectos sociales y culturales.
Sin embargo, el desarrollo -y los procesos de modernización que lo constituyen-implica en sí mismo una constante tensión interna sobre los aspectos sociales, culturales y políticos que sustentan y caracterizan el devenir de una sociedad. Esto quiere decir que, en la medida que los países caminan hacia el desarrollo, se van reconfigurando los cimientos sobre los cuales se solidifican las relaciones sociales, que son las que finalmente permiten canalizar los cambios estructurales que se persiguen.

Esta tensión queda en evidencia cuando se analiza con mayor profundidad las consecuencias del proceso de modernización sobre este sujeto y la subjetividad que lo constituye. El tránsito hacia las sociedades modernas, ha significado cambios profundos que han impactado en las formas de vivir pero también en la operación del pensar -modos de subjetivación- y, a su vez, en los mecanismos de integración y cohesión social, elementos esenciales que condicionan a toda sociedad en vías de desarrollo. Respecto de esto último, Touraine (1999) realizó una periodización de la modernidad ${ }^{3}$, para mostrar las diversas fuerzas centrífugas que fragmentan y dividen a las sociedades y, por otra parte, denominó al proceso de disociación entre economía y cultura como "desmodernización", concepto clave para analizar el alcance que tienen los requerimientos de la economía moderna hacia las relaciones sociales.

La desmodernización es el proceso a través del cual se distancian la racionalidad y la libertad individual a causa de la pérdida de importancia del Estado de derecho, que actuaba como articulador entre estos dos universos. Es decir, los mecanismos clásicos de integración social -o socialización-, como son la escuela, la universidad o la familia, pierden fuerza y quedan reducidos a meros espacios de diferenciación social.

De la idea de desmodernización resulta relevante destacar dos dimensiones que expresan su contenido más profundo: la desinstitucionalización y la desocialización. El primero se entiende como el debilitamiento de los marcos legales que configuran una operación del pensar determinada, con su respectivo marco semántico, a partir del cual se realizan los juicios de normalidad aplicados a esferas sociales definidas por las instituciones. Esto conduce a la emergencia de formas de organización social y conductas culturales que, en virtud de la falta de

\footnotetext{
${ }^{3}$ No obstante, también es posible encontrar otras aproximaciones teóricas, tales como "modernidad o capitalismo tardío" (Habermas, 1999), "modernidad líquida" (Bauman, 2015), "segunda modernidad" y "sociedad del riesgo" (Beck, 1998), "posmodernidad" (Jean-François, 2004), entre otras. Todas estas conceptualizaciones, de alguna forma, ofrecen un tratamiento específico respecto de una problemática general que atraviesa toda la modernidad: la pérdida de la comunidad.
} 
patrones conductuales institucionalizados, coexisten en una diversidad que es, a la vez, inclusiva y excluyente. De esta forma, se configuran costumbres y valores sociales sin mediación normativa, lo que conforma una situación en la cual ya no son las instituciones las que ponen los términos de las relaciones, sino más bien estas quedan determinadas en función del acto de comunicación que se desprende de dichas relaciones.

Ante estos problemas, las ciencias sociales formularon dos respuestas distintas. Por una parte, las corrientes que se derivan de la economía neoclásica y el neoinstitucionalismo (North, 1981, 1990) han planteado que si disminuyen los costos de transacción involucrados en un intercambio, la cooperación y la cohesión social -y por consiguiente, la confianza que la sustenta- se realizarán mediante acuerdos espontáneos. Esto implica que los esfuerzos políticos deberían enfocarse en reducir las barreras que impiden un intercambio fluido, modificando las regulaciones o reglas del juego, o bien estableciendo mecanismos ad hoc para reducir las asimetrías de información. Este tipo de enfoque, conduce a una paulatina reducción del rol del Estado en el desarrollo, en virtud de la incertidumbre y riesgos que genera su intervención en los mercados y en la sociedad.

Por otra parte, hay quienes sostienen (Durkheim, 1928; Putnam et al., 1994; Putnam et al., 2003) que la cooperación y las relaciones de confianza no son el resultado de un intercambio cuyos procedimientos son óptimos en términos de los costos en que se incurren, sino más bien forman parte de las condiciones necesarias que deben concurrir para que todo intercambio sea exitoso. Para que dichas condiciones sean realizables es necesaria la existencia de un conjunto de factores que las promuevan: elementos morales o normativos, representaciones simbólicas en los intercambios, predisposiciones subjetivas, mecanismos de socialización y modos de subjetivación, que orientan la relación de los distintos grupos o actores sociales con la política y lo político (PNUD, 2015).

No obstante estas disquisiciones, es posible avanzar hacia un concepto de cohesión social pertinente para los objetivos de la presente investigación. Para CEPAL (2007), la cohesión social es la dialéctica entre mecanismos institucionalizados de inclusión y exclusión social y las respuestas, disposiciones y posicionamientos subjetivos de la ciudadanía frente a estos procesos y sus resultados, siendo relevante los conceptos de capital e inclusión social, sentido de pertenencia, identidad y solidaridad, la aceptación de normas de convivencia y la disposición a participar en espacios de colaboración, deliberación y proyectos colectivos ${ }^{4}$.

\section{Nuevos paradigmas para el desarrollo territorial}

El desafío del desarrollo, implica para el Estado mayor reconocimiento del potencial y aportes del territorio, como un sujeto activo e interactuante, promoviendo políticas para impulsar el crecimiento, reducir el desempleo, controlar la inflación, reducir la pobreza, garantizar la sustentabilidad y sostenibilidad, mejorar la competitividad y aumentar la equidad y el capital social, entre otros aspectos (Katz, 2008; Moncayo, 2001; CEPAL, 2003; Boisier, 2007).

Al observar el debate conceptual sobre las dinámicas sociales y el accionar del Estado, no cabe duda que la relación entre desarrollo y territorio es una condición necesaria e imprescindible tanto para el actuar público como para el privado. Se trata de una relación simbiótica entre espacio natural y social, producto de lo cual surge la noción de territorio y con ello, los soportes del mismo, que le dan el sustento a la noción endógena de desarrollo y al proceso de descentralización. Sin embargo, el desarrollo territorial no se agota allí, puesto que las relaciones exógenas son también fundamentales para comprender las dinámicas de desarrollo que posee un territorio en particular.

Moncayo (2001), señala que de las dos vertientes que se pueden identificar -una espacial y otra funcional- al parecer están confluyendo hacia una concepción más integral del territorio, por cuanto se la asume como un elemento explicativo del proceso de desarrollo y no un mero factor tangencial del mismo. En ese sentido, los procesos de globalización y descentralización, han estado incidiendo en el posicionamiento de un nuevo paradigma para el desarrollo regional que influye en la forma de entender el territorio. Este se basa en una política que abandona la idea de reformas paliativas que resuelven problemas particulares y avanza hacia una política territorial integral para potenciar la competitividad de las regiones (OCDE, 2009). Es decir, desde una perspectiva de política pública como instrumento para reducir inequidades a otra cuyo ob-

\footnotetext{
${ }^{4} \mathrm{Si}$ bien en un principio el foco de la cohesión social estuvo en la inclusión y exclusión, la pobreza y la vulnerabilidad, los procesos de modernización, principalmente el multiculturalismo y el desarrollo, han empujado a introducir nuevas variables, como la identidades territoriales y la pertenencia. Estas últimas presentan nuevos desafíos para la cohesión social puesto que remiten a espacios locales y comunitarios que exacerban el carácter local del sentido de pertenencia, lo que finalmente juega en contra de la cohesión social entendida en el contexto de una matriz sociopolítica mayor cuyo objetivo es la integración social efectiva.
} 
jeto es el impulso del desarrollo desde las propias regiones a través de múltiples estrategias pertinentes al territorio. De este modo, las políticas regionales integrales contribuyen y son un complemento a las políticas estructurales a nivel nacional.

Este giro en la forma de entender y abordar el desarrollo territorial, supone nuevos desafíos para la sociedad civil, pero especialmente para el Estado nacional y subnacional y sus políticas públicas. Estos se pueden agrupar en dos grandes desafíos: disminuir la desigualdad territorial y mejorar la cohesión territorial.

El primero tiene implicancias sobre el bienestar o las condiciones necesarias que cada territorio debiera tener para reducir las brechas de ingreso, educacional, de salud, de competitividad, entre otras. Para cubrir tales brechas, siguiendo las nociones de Sen (2000), es imperativo recurrir a las capacidades activas y potenciales instaladas, tanto en seres humanos individuales o asociados, como de los territorios en los cuales estos se insertan, en pos de la consecución de las aspiraciones.

Por su parte, la cohesión territorial constituye un desafío por cuanto la instalación de capacidades para el desarrollo requiere de espacios asociativos pertinentes y duraderos, de modo que ninguna persona, independientemente del territorio o localidad donde se encuentre, quede fuera de la posibilidad de acceder a los beneficios que ofrece el país. Las políticas orientadas a fortalecer la cohesión territorial apuntan a otorgarles mayor autonomía a las regiones, con los derechos y obligaciones correspondientes, así como también mejorar sus capacidades colectivas, de innovación, ejercicio de ciudadanía, institucionales y de gestión (Moguillansky et al., 2013).

Habermas (1987) es uno de los pioneros en abordar esta problemática y proponer orientaciones para avanzar hacia sociedades donde exista un reconocimiento mutuo en el campo público. La acción comunicativa tiene por objeto expresar con la mayor exactitud los posibles consensos que pudieran existir entre los actores. Por ello son tan importantes los espacios de convivencia que permiten el reconocimiento mutuo a través de la deliberación. Por lo tanto, la acción comunicativa no tiene como propósito el éxito de una visión particular, sino el entendimiento que surge de la interacción (Habermas, 1987), o bien mejorar la confianza entre los interlocutores, al mostrarse claramente las diferentes posiciones que tienen frente a determinados temas.

Rev. Est. de Políticas Públicas, 2016, 4(noviembre)

\section{Principales barreras para la transformación productiva con orientación territorial}

\section{Cohesión social y territorial}

En Chile, existe un panorama heterogéneo a nivel territorial, que no ha permitido orientar de buena forma las políticas públicas que pretenden fortalecer las capacidades territoriales. Hay regiones que, dado los recursos naturales que poseen, tienen ingresos per cápita que alcanzan los niveles de países desarrollados, mientras hay otras que, en virtud de la carencia de recursos de este tipo, no han logrado fortalecerse. Por lo tanto, lo que existe más bien es una diversidad de situaciones económicas, sociales y culturales que impiden aplicar políticas neutrales para resolver los problemas, así como también para iniciar cambios estructurales. A esto hay que sumarle la gran concentración de la población en la Región Metropolitana, junto con ser el país más centralizado de América Latina (SUBDEREUFRO, 2012). Ciertamente, el sector público es centralizado, jerárquico, sectorial y uniforme, lo que deja a los gobiernos regionales y locales, junto con la sociedad civil, en un escenario muy débil y precario para enfrentar cualquier desafío de transformación productiva u otro desafío similar. Esto último, sin embargo, no se limita solamente al Estado, sino también es un elemento distintivo del sector privado del país.

Esto se ha traducido en una disparidad de situaciones que se reflejan en diferentes variables: cobertura de educación, índices de pobreza e indigencia, tasa de desempleo, PIB regional, índice de competitividad, atracción y retención de capital humano e inversiones, capacidades de gestión pública, entre otros.

En el contexto de la globalización, que impone un juego de supervivencia a la luz de una competitividad cada vez más despiadada, las regiones han debido responder de forma rápida y oportuna a distintos requerimientos, sin embargo, las capacidades para que dichas respuestas sean efectivas han sido variadas. Así, por ejemplo, el índice de competitividad regional (SUBDERE-UFRO, 2012) muestra los dispares resultados que presentan los territorios y localidades en este ámbito. Mientras la Región Metropolitana concentra la mayor parte de las inversiones, infraestructura, atracción de capital humano, lo que determina el alcance de su competitividad, existen otras regiones que no son capaces de competir con estos mismos recursos en este nuevo escenario. 
Al respecto, cabe señalar que la globalización no sólo tiene efectos negativos sobre la desigualdad territorial, puesto que muchas veces aumenta las brechas entre estos, sino también sobre la cohesión social. Es decir, la globalización, en el marco del proceso de modernización que lo contiene, ha modificado las tradicionales formas de construcción de las identidades culturales y territoriales al trastocar el modelo institucional bajo el cual tenían sentido y los mecanismos de integración y cohesión social.

Un estudio de la Universidad de Chile ${ }^{5}$, en conjunto con la SUBDERE (Espinoza, 2009), desagrega el capital social en cuatro dimensiones: asociatividad, interés en la política, confianza y redes personales. En el ámbito de la confianza, destacan dos subdimensiones: a las instituciones y la interpersonal. Del análisis de estas últimas, se concluye que las oportunidades de empleo y emprendimiento que ofrecen las regiones están condicionadas por las capacidades de coordinación y colaboración de la sociedad civil, lo que a su vez depende de la densidad del capital social, particularmente las relaciones de confianza, que pudiera encontrarse en un territorio determinado. Frente a ello, la mayor parte de las regiones poseen escasos niveles de confianza interpersonal y serias dificultades en la confianza en las instituciones. La ausencia de estos elementos fundamentales del capital social, termina por aumentar los costos de transacción (Espinoza, 2009) y retrasar aún más el tránsito hacia una mayor descentralización y el inicio del cambio estructural para la transformación productiva.

La desigualdad territorial y la capacidad de desarrollo endógeno, también se evidencia en la concentración de matrícula de educación superior y la retención de capital humano en las regiones. Mientras en la Región Metropolitana la participación en la matrícula total asciende a un $47 \%$, le siguen de lejos Bío-Bío con $13 \%$ y Valparaíso con $12 \%$, en el resto de las regiones dicha participación varía entre un $5 \%$ y $0,1 \% \%^{6}$. Una de las causas principales para este proceso de concentración de la matrícula, es la fuga de estudiantes que terminan la educación secundaria hacia las zonas metropolitanas. Las personas optan por cambiar de región en virtud de las mejores oportunidades que ofrecen en términos de empleos, remuneraciones y expectativas de mejoramiento continuo en la calidad de vida.

Por último, esto tiene efectos sobre el carácter de las políticas que se aplican tanto para solucionar los problemas más urgentes, así como también aquellas que son utilizadas para promover cambios estructurales. Se requiere avanzar hacia la superación de políticas neutrales para llegar a otras basadas en

\footnotetext{
${ }^{5}$ En el marco del Proyecto Desigualdades (Anillo SOC12).

${ }^{6}$ Datos obtenidos de SIES.
}

las particularidades de cada territorio.

\section{Algunos resultados de las estrategias de desarrollo}

En el último tiempo, los organismos del Estado han elaborado diversas estrategias para avanzar hacia el desarrollo y, por consiguiente, mejorar la competitividad del país. Todas estas han abordado distintas materias y han considerado los diferentes niveles involucrados, esto es, lo nacional, regional y local, con el objetivo de operacionalizar las políticas, programas y proyectos que deben aplicar. De esta naturaleza, es la Estrategia Nacional de Innovación -en sus diferentes versiones- y la Agenda de Productividad, Crecimiento e Innovación, así como también las Estrategias Regionales de Desarrollo y de Innovación. A partir de ellas se han diseñado y aplicado diversas políticas de fomento y desarrollo productivo, innovación y ciencia y tecnología, entre otras, las que han contribuido a instalar la necesidad de un nuevo tipo de desarrollo a nivel nacional y regional a partir de las directrices definidas.

Con respecto a las políticas de promoción productivas, estas se basan en una concepción liberal del rol del Estado en la economía, siendo este sólo una suerte de distribuidor de recursos para una promoción productiva de características más bien neutra, o en otros términos, basadas exclusivamente en una política industrial pasiva (CEPAL, 2014) cuyo objetivo es distribuir recursos sin discriminar entre actividades. Esta orientación se reafirmó y consolidó durante los años noventa y dos mil, sin perjuicio que durante esta última y en adelante, se producen algunas orientaciones que modifican de alguna forma el rol estatal en el fomento productivo, avanzando hacia una política industrial horizontal, pero esta vez más activa con el objetivo de corregir las fallas del mercado (CEPAL, 2014), así como también introduciendo la preocupación de la articulación de los actores en los territorios (González, 2012); esto, por cierto, sin desprenderse del paradigma liberal que lo constituye.

En ese sentido, en los años noventa se ampliaron las posibilidades de instrumentos para el desarrollo productivo sobre la base de la inserción de las micros, pequeñas y medianas empresas en los mercados respectivos, la diversificación de las exportaciones y la innovación tecnológica (Muñoz, 2009) ${ }^{7}$. En la base de estos propósitos, estuvo la horizontalidad de los instrumentos, esto es, la disponibilidad

\footnotetext{
${ }^{7}$ Entre las principales políticas impulsadas en esta década se encuentran el Fondo de Desarrollo Tecnológico, el Fondo para el Desarrollo Innovador, el Fondo de Asistencia Técnica, el programa Todo-Chile, los Proyectos de Fomentos (PROFO), entre otros.
} 
de recursos para todas aquellas empresas que quisieran acceder a los fondos en forma de subsidios, sin necesidad de una estrategia u orientación previa acerca de dónde invertir o difuminar los esfuerzos. Adicionalmente, estas políticas respondieron a los requerimientos de una economía basada en la explotación de los recursos naturales y, a la vez, no hicieron mayor diferencia entre las regiones, sectores y actividades productivas. Por medio de estos instrumentos, se revela el carácter neutral de las políticas de fomento productivo con un Estado que abandona el rol más activo respecto de seleccionar y apostar sobre el desarrollo de algunos sectores a la luz de un cambio estructural.

Sin perjuicio de lo anterior, es posible encontrar algunas políticas focalizadas cuyo objetivo fue potenciar ciertos sectores, las mayorías de las cuales estuvieron orientadas hacia los recursos naturales, como la minería, la pesca artesanal, el fomento rural agrícola y extra agrícola, y en algunos servicios, como el comercio. Esto quiere decir que, si bien en la década de los noventa existió una preponderancia de políticas e instrumentos que respondieron al paradigma liberal, también se aplicaron políticas cuya selección de promoción se realizaba de forma a priori. La convivencia de ambas lógicas, no se tradujo en el tránsito de una hacia la otra, sino más bien en la transposición de ellas en el marco económico y legal de corte liberal. Esto queda en evidencia al observar la unidad objetivo de estas políticas, que fueron principalmente la empresa y el empresariado, en desmedro de una mirada más integral del desarrollo, el que incluye un enfoque territorial y la articulación de los actores con su correspondiente prioridad en términos productivos y comerciales.

De la experiencia y lecciones de estas políticas, programas e instrumentos, se expresó la necesidad de contar con una mayor articulación entre los actores participantes. Este primer acercamiento se caracterizó por una forma de articulación mediada fundamentalmente por el mercado, es decir, sobre la base de resolver fallas de mercado y buscar la convergencia entre oferta y demanda, lo que convertía a esta articulación, finalmente, en efímera y circunstancial.

En la década siguiente, la atención radicó en la introducción de encadenamientos entre agentes y actividades, cuestión que se expresa en una política de promoción más activa y focalizada en las exportaciones tradicionales de recursos naturales y cadenas productivas a nivel regional (González, 2012). De esta forma, se introduce con gran elocuencia la perspectiva de los polos productivos o cluster para incentivar sectores en regiones que tuvieran la potencialidad adecuada para ello. Con esta idea, también se pretendía integrar a las pequeñas y me- dianas empresas a los encadenamientos en torno a los polos productivos que se definan. Frente a ello, comienza a tomar fuerza el desarrollo productivo a nivel regional y territorial y se instala la necesidad de contar con una institucionalidad adecuada para avanzar hacia esto.

En ese contexto, en CORFO, como el principal organismo público encargado del desarrollo productivo, se hacen presente dos orientaciones que van a ser fundamentales para las ulteriores políticas. Por una parte, la necesidad de mayor coordinación intersectorial entre los organismos que se vinculan al fomento productivo ${ }^{8}$; y por otra parte, que el impulso de estas políticas debería ser realizado en una interacción entre el sector público y privado a través de instancias de colaboración en el marco de una nueva gobernanza del fomento productivo.

De esta mirada histórica a las políticas de fomento productivo, se puede concluir tres cosas fundamentales para el análisis. En primer lugar, una economía basada en los recursos naturales no solo genera distorsiones macroeconómicas y sociales, sino también permea las políticas que tratan de enfrentar su superación. En segundo lugar, si bien es posible encontrar políticas selectivas, lo que ha predominado son políticas horizontales y neutras en torno al desarrollo económico, basadas en los principios del mercado. En tercer lugar, tanto el enfoque territorial como la necesidad de la articulación de los actores a nivel territorial, han incidido en las políticas de desarrollo productivo, instalando nuevas formas institucionales en las regiones del país.

En el caso de las políticas de innovación, ciencia y tecnología, los resultados indican que ha habido un gran esfuerzo en ampliar la oferta de formación especializada, aumentar y mejorar el capital humano en ciencia y el gasto en personal de investigación y desarrollo $(\mathrm{I}+\mathrm{D})$. Si bien en el periodo analizado la matrícula total de magíster prácticamente se ha duplicado, su distribución se encuentra bastante concentrada en sólo tres regiones de las quince existentes: Región Metropolitana, Valparaíso y BíoBío. Lo mismo ocurre con la matrícula de doctorados pero con un crecimiento menor y una matrícula total aún baja en relación a los programas de magíster ofrecidos.

Por otra parte, el número de académicos jornada completa equivalente (JCE) si bien ha crecido en el periodo analizado, lo ha hecho en menor medida que la matrícula de postgrado. A ello se suma que nuevamente la Región Metropolitana, Bíobío y Valparaíso concentran gran parte de los académicos

\footnotetext{
${ }^{8}$ Principalmente, CORFO, INDAP, FIA, SENCE, SERCOTEC, FOSIS, SERNATUR, Ministerio del Exterior, Ministerio de Minería, Ministerio de Economía, entre otros.
} 
del país. Respecto a las universidades, en general se observa que, independientemente de su propiedad (privada o estatal), hay una importante presencia a nivel regional de las instituciones privadas. No obstante lo anterior, estas últimas si bien se distribuyen a lo largo del país, lo hacen principalmente a través de sedes, en la medida que sus casas centrales se ubican en la Región Metropolitana. Las instituciones estatales, en cambio, se distribuyen por todo el territorio con sus respectivas casas centrales en cada región.

Una mirada al panorama de la educación superior muestra que el país no se ha dotado de las capacidades necesarias para generar las posibilidades de transformación productiva en el marco de la sociedad del conocimiento. Si se entiende que la investigación y desarrollo es parte fundamental para difuminar las opciones que luego se concretan en la diversificación productiva, se puede concluir que dicha base o soporte no ha alcanzado el nivel suficiente para responder adecuada y oportunamente a estos requerimientos. Esto se expresa en los siguientes fenómenos: (i) formación técnica enfocada a la docencia; (ii) emergencia de universidades minimalistas; (iii) precarización de las universidades de investigación; (iv) y la masificación de estudiantes a través de instituciones de calidad deficiente.

Por último, resulta relevante analizar los recursos invertidos y el personal dedicado a las actividades de investigación y desarrollo en el país, en particular en las empresas, Estado, instituciones de educación superior e instituciones privadas sin fines de lucro ${ }^{9}$. La inversión en $\mathrm{I}+\mathrm{D}$ es una forma de incentivar la innovación y negocios en pos de mejorar la competitividad en el mercado y crear, de esta forma, una cultura de innovación, principalmente en las empresas. Chile invierte en total un 0,39\% del PIB en $\mathrm{I}+\mathrm{D}$, porcentaje muy por debajo del promedio de los países de la OCDE, cuya inversión alcanza al $2,4 \%$.

Adicionalmente, al observar la fuente de financiamiento se constata que es el Estado quien hace el mayor esfuerzo para incentivar la I+D en el país. Entre 2007 y 2013, el Estado explica el $63 \%$ del incremento total, mientras que las empresas el $29 \%$, lo que evidencia una estructura productiva cuyo sector empresarial aún no avanza decididamente hacia una transformación productiva basada en el conocimiento e innovación.

Si se mira el gasto en $\mathrm{I}+\mathrm{D}$ en función de las entidades ejecutoras durante el año 2013, se aprecia que

\footnotetext{
${ }^{9}$ Estos son los sectores a los que se aplica la Encuesta sobre gasto y personal en I+D, aplicado por el Instituto Nacional de Estadística (INE) y coordinado por el Ministerio de Economía.
}

en las universidades recae el mayor gasto, un $39 \%$ del total, siguiéndole las empresas con un $36 \%$, y de lejos los observatorios y las instituciones privadas sin fines de lucro, con un $8 \%$ del total.

Uno de los aspectos fundamentales para avanzar hacia una sociedad y economía del conocimiento, es que los esfuerzos que se realicen, como es el caso del gasto en $\mathrm{I}+\mathrm{D}$, consideren de forma prioritaria los sectores que generan mayor valor agregado. Sin embargo, los sectores basados en los recursos naturales reciben aproximadamente un tercio del gasto total en I+D. Si se considera sólo a las empresas, sucede algo similar, por cuanto estos sectores siguen teniendo un peso relevante en el conjunto de las actividades económicas del país.

Al igual que en el resto de los datos analizados por región, el gasto en $\mathrm{I}+\mathrm{D}$ sigue el mismo patrón, es decir, la Región Metropolitana concentra el $58 \%$ del gasto, Valparaíso el $11 \%$ y Bío-Bío el $6 \%$. En específico, la explicación radica esencialmente en la concentración de la producción de valor, debido a que en la R.M. se produce el $47 \%$ del PIB nacional.

Hasta ahora se han analizado los resultados de las políticas de desarrollo productivo, innovación, ciencia y tecnología respecto de los sectores vinculados a la generación del conocimiento, sin embargo, es necesario avanzar un poco más y mostrar el panorama relacionado a la innovación y emprendimiento en la economía en general. La tasa de innovación ${ }^{10}$ según sector económico muestra que la hegemonía de los recursos naturales está incluso presente en los procesos que buscan superar su relevancia; de esta forma, los sectores que tienen mayor tasa de innovación son energía (50\%) y minería (45\%), y en tercer lugar la industria manufacturera (33\%); lo anterior en el contexto de una tasa de innovación total de $23,6 \%$.

La tasa de innovación puede desagregarse en innovación tecnológica, que comprende productos y procesos, y la innovación no tecnológica, que incluye la innovación organizacional (gestión) y marketing. De los datos analizados se constata que, en primer lugar, ambos tipos de innovación tienen tasas similares y, en segundo lugar, que la innovación de procesos es la que predomina en el conjunto, esto es, la implementación de un nuevo o mejorado proceso de producción, método de distribución o actividad de soporte para los bienes y servicios. Esto explica en parte el hecho de que la estructura productiva del país no genere mayor valor, puesto que está enfocada en optimizar los procesos ya instalados, lo que finalmente apunta a mejorar la produc-

\footnotetext{
${ }^{10}$ En este caso se entiende como el porcentaje de empresas que realizaron algún tipo de innovación sobre el total de empresas.
} 
tividad más que otra cosa. Por lo tanto, es posible concluir que en general las innovaciones-tecnológicas son más bien adaptación de tecnologías que la introducción de nuevas en el marco de transformación productiva de las empresas o el mercado.

La misma encuesta arroja resultados interesantes respecto del proceso de innovación, al establecer que la mayor parte de las innovaciones de productos y procesos se realizaron al interior de la empresa, siendo escasa la colaboración entre estas y el resto de las instituciones públicas, de conocimiento $\mathrm{u}$ otras. Al respecto, de las empresas que innovaron en productos, sólo el $13 \%$ lo hicieron con terceros, mientras que las que innovaron en procesos sólo un $8,8 \%$ lo hizo bajo esta modalidad. Esto se refuerza con el hecho que tan sólo el 7,3\% de las empresas que innovaron señalan que realizaron alguna actividad de cooperación con otras instituciones, en los años 2011 y 2012; el resto $(92,7 \%$ ) dice simplemente que no realizó ninguna acción de cooperación. Asimismo, las empresas que realizan innovación en conjunto con otras instituciones lo hacen principalmente con otras empresas de su mismo rubro (47\%), mientras que las relaciones con universidades o instituciones de investigación es baja, tanto nacional como internacionalmente.

Por otra parte, al observar otros elementos que derivan de la innovación, como son el uso de patentes y los derechos de propiedad intelectual, se observa que la minería lidera fuertemente este mercado y, por lo tanto, concentra el impacto de las innovaciones. De esta forma, de las empresas que han innovado y han utilizado las patentes disponibles un $26 \%$ provienen del sector minero; mientras que en la solicitud y concesión de algún tipo de derecho de propiedad la minería también lleva la delantera, con un 8,3\% en el país y un $3,3 \%$ en el extranjero.

En la dimensión regional, se aprecia una tasa de innovación heterogénea pero no necesariamente concentrada en pocas regiones. Es interesante observar el porcentaje de empresas que innovan y que, a la vez, lo hacen a través de acciones de cooperación por región. La Región Metropolitana y la Región del Bíobío lideran las actividades de innovación que realizan en conjunto con otra institución.

\subsection{Descentralización del desarrollo productivo}

Al analizar el caso de las Agencias Regionales de Desarrollo Productivo (ARDP) -o en algunos casos denominadas corporaciones- en el contexto de la transformación productiva, necesariamente se tiene que abordar el marco institucional sobre el cual descansan sus objetivos de política.

La política de descentralización del desarrollo productivo se basa en dos marcos institucionales que le son propios para explicar su contexto de desempeño: por una parte, la institucionalidad pública para el desarrollo productivo, en términos de su estrategia, diseño y ejecución de políticas y programas; y por otra parte, el marco que norma la relación entre los distintos niveles de los gobiernos central, regional y local.

A nivel de estrategia no se evidencia una instancia permanente que defina una mirada de largo plazo para el desarrollo productivo del país, quedando radicado en CORFO la responsabilidad de impulsar las políticas y programas dentro del marco normativo existente.

La carencia de una instancia de definición estratégica del desarrollo productivo queda en evidencia cuando se desarrollan las agendas de políticas que se aplican durante un periodo presidencial: éstas son elaboradas por los organismos sectoriales, en este caso el Ministerio de Economía y, por lo tanto, dependen de las autoridades elegidas para tales propósitos. El Consejo Nacional de Innovación para el Desarrollo (CNID) ${ }^{11}$ de alguna forma ha llenado este vacío, no obstante, la consolidación de sus objetivos ha sido insuficiente en virtud de los cambios conceptuales que ha sufrido desde que fue gestado y que han reconfigurado el escenario para las políticas de desarrollo productivo. Adicionalmente, cuando fue conformado no se le entregaron las facultades y atribuciones necesarias para efectivamente liderar el proceso de desarrollo en base a la innovación.

A nivel de definición de políticas, el Ministerio de Economía es el facultado para normar su diseño y aplicabilidad y, en el marco de acción constituido, la tarea de orientar las políticas ha sido función de CORFO.

A este organismo público se le suma el Servicio de Cooperación Técnica (SERCOTEC) y el Servicio Nacional de Turismo (SERNATUR), ambos dependientes del Ministerio de Economía. Además, es importante destacar la presencia de la Comisión Nacional de Ciencia y Tecnología (CONICYT), que depende del Ministerio de Educación; la Fundación para la Innovación Agraria (FIA), agencia de fomento de la innovación del Ministerio de Agricultura, y el Servicio Nacional de Capacitación y Empleo (SENCE) dependiente del Ministerio del Trabajo. Cada uno de estos organismos desarrollan su agenda de trabajo a través de sus respectivos ministerios, o bien algunas logran actuar de forma más

\footnotetext{
${ }^{11}$ Antes denominado Consejo Nacional de Innovación para la Competitividad (CNIC)
} 
autónoma (en el caso de CORFO), sin embargo, no existe ninguna instancia permanente con poder real de coordinación para el desarrollo productivo (Moguillansky, 2010).

$\mathrm{Al}$ contrastar esta situación con los tres principios básicos que deben converger en el marco institucional para la realización de una transformación productiva (Devlin y Moguillansky, 2010), se constatan diferentes problemas. Al analizar la capacidad de liderazgo y coordinación de los organismos públicos; capacidad de generar alianzas públicoprivadas; y la capacidad de diseñar una estrategia de mediano y largo plazo con sus respectivas políticas, programas e incentivos; se asoman los problemas que devienen en el marco institucional para el desarrollo productivo.

\section{Las Agencias Regionales de Desarrollo Productivo}

Las Agencias Regionales de Desarrollo Productivo nacieron en 2006 durante el primer gobierno de Michelle Bachelet con el propósito de contribuir a la descentralización de las decisiones para el desarrollo productivo, asegurando la articulación de las empresas, organismos públicos y sociedad civil, en torno a los aglomerados productivos o cluster (González, 2012).

Es en el plano de los objetivos de esta política donde se visualizan las barreras económicas, sociales e institucionales analizadas en las secciones anteriores, que afectan su efectivo cumplimiento. En la medida que la economía nacional depende en buena parte de la renta que generan los recursos naturales, los empresarios y empresas que se conforman a nivel regional tienen poco o nada de poder de influencia sobre la transformación productiva, puesto que la mayoría de las grandes empresas tienen su domicilio en la Región Metropolitana y se vinculan fuertemente con los recursos naturales, con presencia nacional e internacional, mientras las medianas y pequeñas empresas regionales participan en los encadenamientos productivos de estas mismas empresas, y las menos, intentan crear nuevos espacios de negocio y producción pero sin las suficientes capacidades e influencia a nivel nacional y regional. Las diferencias de influencia y poder entre las primeras y las segundas son evidentes, motivo por el cual las instancias de colaboración público-privadas quedan tensionadas por esta realidad.

Por lo tanto, las ARDP han quedado sometidas a estas lógicas, vacíos y problemas estructurales, que se resumen en las diferencias de influencia, po- der y perspectivas que tienen los actores que participan en la definición de las agendas estratégicas de desarrollo productivo. Los gobiernos regionales, los empresarios de distinto tamaño y rubro, y las instituciones de investigación operan bajo lógicas e intereses distintos, que pocas veces coinciden. Pese a que existen argumentos para sostener que se requiere impulsar una política de descentralización de desarrollo productivo, no es evidente que las ARDP, y sus continuadoras, sean las más apropiadas para cumplir dicho propósito, y responder al desafío de la transformación productiva territorial en los términos y productos requeridos. A juicio de algunos expertos, las ARDP están sometidas a un marco institucional y a una voluntad política todavía muy centralizadora que no les permite lograr sus objetivos y, por ende, requieren de medidas en paralelo que fortalezcan su quehacer.

Para indagar en las dificultades de la implementación de esta política, en función de su pertinencia y las perspectivas de transformación y diversificación productiva que trae consigo, se han seleccionado dos regiones paradigmáticas. El criterio utilizado se basa en los supuestos teóricos planteados a lo largo de esta investigación, que dicen relación con la escasa diversificación productiva y una baja cohesión social en los territorios del país. En ambos casos es interesante observar las regiones que, en uno u otro plano, tienen una presencia destacada de estas variables, o bien una presencia deficiente, a fin de preguntarse sobre las razones de esta situación y su relación con la condición actual de la agencia regional de desarrollo productivo.

Es interesante, por lo tanto, contrastar una de las hipótesis que se ha planteado en el último tiempo en torno a la descentralización del desarrollo productivo y que se asume en esta investigación, que sostiene que la implementación efectiva de una política industrial y la articulación público-privada se presenta en territorios cuya estructura productiva y capital social es robusto y denso (Moguillansky, 2010).

Se han seleccionado las regiones de Valparaíso y Coquimbo, las que si bien se encuentran en la misma macrozona (norte), muestran un contraste importante en términos de estructura productiva y capital social. Por lo tanto, interesa indagar en por qué una región como la de Coquimbo, cuya diversificación productiva y capital social han sido insuficientes, tiene al mismo tiempo una corporación de desarrollo productivo que opera de buena forma, y, por el contrario, una región como la de Valparaíso, con una diversificación productiva y capital social satisfactorios pero que no ha logrado consolidar una instancia que promueva el desarrollo productivo y la articulación público-privada. 


\section{Región de Valparaíso}

Los factores que influyen en la economía regional y, por lo tanto, en el quehacer de una agencia dedicada al desarrollo productivo, son variados y su importancia depende de las particularidades de cada región. Los siguientes factores explican los rasgos principales de una economía y su capacidad para mejorar la competitividad (SUBDERE-UFRO, 2012 ; 2013; 2014): calidad de las empresas, de la infraestructura, los servicios financieros, la diversidad de recursos naturales y humanos, la capacidad de innovación y su transferencia, la producción cultural y artística y, por supuesto, la calidad de los servicios públicos, radicados principalmente en los municipios y gobiernos regionales, así como también en toda la estructura institucional sectorial desconcentrada.

Al considerar estos factores, la región de Valparaíso, a juicio de los expertos, ha logrado desarrollar de manera adecuada algunos de estos aspectos, sin embargo, resultan preocupantes el estado actual de otros. Entre los factores destacados se encuentra, en primer lugar, el sistema de educación superior de la región, en función de su complejidad, la diversidad de oferta formativa y la capacidad que tiene para responder a las diversas necesidades y demandas regionales a través de la investigación, la innovación y un cuerpo académico y profesional destacado; se aprecia, además, la capacidad para crear espacios comunes que se constituyan como un vínculo para el fortalecimiento de la educación superior de la región ${ }^{12}$; en segundo lugar, se destaca, como muestran los datos que caracterizan a la región, la diversidad de sectores productivos que conforman la economía regional y con ello el establecimiento de numerosas empresas con sus respectivas asociaciones gremiales, las que si bien no tienen una mirada de conjunto y de largo plazo se preocupan de compartir información y, en ocasiones, defender sus intereses corporativos.

En el caso de los factores que se aprecian debilitados, uno de los entrevistados sostiene que "la experiencia es que hay mucho discurso y poca acción. Por ejemplo, las mesas regionales que derivaron a las agencias: es lamentable que no se haya concretado la corporación que continuaba con el trabajo de la Agencia Regional de Desarrollo Productivo". Asimismo, otro de los entrevistados señala, en el mismo sentido: "cuesta generar un diálogo más estratégico en torno al desarrollo regional; no existen las instancias; falta una instancia de participación más activa".

\footnotetext{
${ }^{12}$ Se destaca, en este caso, la existencia de un Consejo de Rectores de la región de Valparaíso.
}

Es decir, si bien se valora la existencia de instancias formales de articulación público-privadas, como era la Agencia Regional de Desarrollo Productivo de Valparaíso, se ve con preocupación la incapacidad que hay en la región para potenciar y fortalecer espacios formales de este tipo. Si bien se tienen, por una parte, instituciones de educación superior con capacidades investigativas, y por otra parte, un sector privado dinámico y preocupado de enfocarse en la innovación para mejorar la productividad, los esfuerzos se encuentran dispersos y fragmentados, lo que constituye una pérdida de recursos y de mirada estratégica. En general, no existen vinculaciones permanentes entre estos dos sectores y lo que se da más bien es un vínculo funcional de carácter consultivo cuyos objetivos apuntan a resolver aspectos puntuales de los procesos productivos. Las lógicas que mueven la acción y que fundamentan los objetivos de ambos sectores no logran coincidir dados los escasos incentivos financieros e institucionales que existen (SUBDERE, 2014).

Según un estudio que analiza el capital social y el civismo en las regiones (Espinoza, 2009; SUBDERE, 2011), la región de Valparaíso destaca dentro de aquellas que posee un capital social robusto y consolidado, por lo menos en términos de confianza interpersonal. Esto indica, en general, que las relaciones sociales que concurren en la región podrían facilitar el desempeño económico.

A juicio de algunos entrevistados, a pesar de la existencia de capacidades instaladas y de relaciones virtuosas entre los actores regionales, que se expresan en diferentes iniciativas en conjunto, la articulación para el desarrollo productivo no se ha logrado materializar de buena forma y lo que prevalece más bien son asociaciones o vínculos funcionales, efímeros y relativamente dispersos. Uno de los entrevistados se hace la pregunta en el contexto de la desarticulación existente entre las universidades de la región y responde de forma enfática: “¿cómo articular a los distintos actores si los incentivos institucionales apuntan a lo contrario? El problema de la desarticulación no es institucional (existe el Consejo de Rectores de las Universidades de Valparaíso) sino más bien cultural: desconfianzas ${ }^{13}$ Tiene que existir una mirada de sistema donde nos pongamos de acuerdo en los ámbitos de acción y quienes puedes responder de la manera adecuada a ellos".

De esto, se puede concluir que el problema va más allá del desencanto y desconfianza recíproca entre los ciudadanos y las instituciones políticas y socia-

\footnotetext{
${ }^{13}$ Otro de los entrevistados describe de esta forma el problema: "Este modelo (el de las agencias regionales de desarrollo productivo) está muy probado en el mundo pero en Chile no resultó, cada uno cuida su metro cuadrado, empezamos a desconfiar y cada cual quiere sacar su pedazo de la torta".
} 
les, y radica más bien en la forma en que se despliega la idea de democracia y, por lo tanto, la gobernabilidad a partir de la cual descansa dicha relación, que a nivel regional se inscribe en una institucionalidad pública predominantemente desconcentrada y limitadamente descentralizada y autónoma.

Siguiendo las tres líneas temáticas planteadas por Moguillansky (2010) para analizar la implementación de una política industrial en términos institucionales, esto es: el liderazgo del sector público regional, la articulación público-privada y las estrategias de largo plazo; se tienen los siguientes resultados para la región de Valparaíso, a partir de las voces de sus principales actores.

En cuanto al liderazgo regional, la ley sobre Gobierno y Administración Regional establece que los responsables del desarrollo económico, social y cultural de las regiones son los Gobiernos Regionales (GORE), los que además son los encargados de definir la Estrategia Regional de Desarrollo, dentro de la cual se desprenden las orientaciones para el desarrollo productivo regional. Estas atribuciones, sin embargo, si bien han sido realizadas en la mayoría de las regiones, algunas no han avanzado en la implementación de dicha estrategia, lo que se explica principalmente por la falta de atribuciones que posee el GORE para aplicar las políticas, y que se evidencia como uno de los principales vacíos que establece la ley respectiva. Esto redunda en una incapacidad de liderazgo regional para definir e implementar las políticas de transformación productiva, desplazándose la responsabilidad y toma de decisiones a la estructura nacional y, por lo tanto, transformando a la institucionalidad pública regional en meros ejecutores y demandantes de instrumentos, mecanismos, programas y recursos de política ya trazadas. Adicionalmente, predomina un enfoque sectorial a cargo de diferentes ministerios pero que tienen ninguna coordinación a nivel regional y, menos aún, con liderazgo del GORE. Esta falta de coordinación conduce, entre otras cosas, a una duplicidad y vacíos en las políticas de desarrollo productivo, por cuanto se ejecutan políticas, programas y proyectos en distintos momentos con objetivos similares, o también, y asociado a lo anterior, se dejan de enfrentar problemas y desafíos a raíz de la escasa prioridad que se le dan por parte de los actores participantes y agentes del desarrollo (SUBDERE, 2014; Arredondo et al., 2013).

Respecto de las alianzas público-privadas, como se ha sostenido, se encuentran completamente debilitada, por varios motivos. Desde el punto de vista de los actores, el sector privado de la región si bien es heterogéneo, no se encuentra coordinado en pos de un desarrollo productivo común, cuestión que se explica, entre otras cosas, porque las grandes em- presas presentes en el territorio tienen su casa central en la región Metropolitana. En el caso de las universidades, surgen las siguientes interrogantes en relación a la articulación con el sector público de la región, como lo expresa uno de los entrevistados: El tema es desde dónde se arma la plataforma para realizar las articulaciones, ¿es la universidad la que reacciona, o bien es el sector público el que convoca? ¿Quién tiene que convocar? Debiera ser la institucionalidad pública.

Respecto de la definición y elaboración de estrategias de desarrollo con sus respectivas políticas y programas, es posible sostener que los actores regionales reconocen la existencia de lineamientos, tales como la necesidad de mejorar la productividad, la competitividad, la diversificación exportadora y, en este último tiempo, el emprendimiento y la innovación, como discursos presentes en la política pública del país, sin embargo, la aplicación de estas temáticas se ha realizado con instrumentos de diversa índole que, en su sumatoria o agregación, no se desprende ninguna estrategia o visión de largo plazo a partir de la cual se pueda realizar una traducción y priorización con base regional y territorial. De esta forma, la Estrategia Regional de Desarrollo de Valparaíso es más bien un documento formal que establece prioridades pero que, finalmente, al prevalecer la lógica sectorial se transforma en irrelevante, mientras que su capacidad para sustentar una política industrial es prácticamente nula, según señalan los actores de la región.

\section{Región de Coquimbo}

Respecto de la industria minera, cabe destacar que la región ha sufrido los vaivenes que significa basar su actividad económica en este tipo de industria. A finales de los años noventa, con el inicio del proyecto Pelambres en la provincia de Choapa, el sector presentó un crecimiento de un $218 \%$ de un año a otro respecto de su participación en el PIB regional. En los años siguientes su crecimiento y participación ha variado en función de las crisis económicas y los ciclos del precio del cobre. Sin embargo, esta situación, de convertirse tan rápidamente en una región rentista, ha impactado en su desarrollo económico y productivo, relegándola a los últimos lugares a nivel nacional, según el índice de competitividad regional (SUBDERE-UFRO, 2012).

Al observar el panorama de la educación superior en la región de Coquimbo, si bien hay una buena cantidad de instituciones, muchas de ellas no tienen la casa central en la región y, además, solo realizan la función docencia, elementos que no contribuyen 
ni a la identidad regional y menos aún al fortalecimiento de las capacidades para la generación de investigación, desarrollo e innovación. Aquellas instituciones que tienen presencia exclusiva en la región tampoco muestran las capacidades suficientes en materia de investigación, elemento esencial para la generación de conocimiento, que es la base para cualquier transformación productiva con base territorial.

De esta forma, las empresas regionales presentan los mismos rasgos problemáticos que provienen del centralismo: la mayoría de las empresas tienen su casa matriz fuera de la región. Esto, como se ha visto, perjudica principalmente en el impacto que pudiera tener en el desarrollo productivo la articulación público-privada. Este fenómeno se aprecia como uno de los principales factores, en términos de la configuración económica de la región, que impiden avanzar fructíferamente en la articulación de los actores regionales para el desarrollo productivo.

Según el estudio sobre capital social regional (Espinoza, 2009; SUBDERE, 2011), la región de Coquimbo presenta un capital social deteriorado y se ubica en el lugar más bajo del país en todas las dimensiones consideradas. Esto quiere decir, de acuerdo al enfoque del capital social, que en este territorio es más difícil establecer iniciativas que involucren la coordinación y articulación, motivo por el cual la acción colectiva para el desarrollo enfrenta dificultades crecientes (SUBDERE, 2011).

Sin duda la carencia de capital social permea la capacidad de coordinación para un proyecto común, lo que unido a los factores económicos que presenta la región, abocados principalmente a la explotación de recursos naturales, condiciona la idea de desarrollo en su conjunto. Por supuesto, no hay evidencia que indique que un débil capital social se explique por el patrón productivo de la región, o por otros factores posibles, pero sin duda es una combinación de ellos que impactan en mayor o menor medida en función de las particularidades de cada territorio. Esta situación, de presencia deficiente de capital social y diversidad productiva, es la que caracteriza a la región de Coquimbo.

El positivo liderazgo que se destaca del GORE tiene algunas situaciones que se deben resolver, a fin de mejorar su posición dentro de la región y, en particular, en su propósito de promotor del desarrollo productivo de la región.

En lo que respecta a la articulación públicoprivada, se evidencia una positiva interacción entre los diferentes actores regionales vinculados al desarrollo productivo, esto es, las empresas, instituciones de educación superior y el sector público, exis- tiendo incluso instancias específicas que los reúnen, en función de sus intereses, objetivos y perspectivas temáticas.

Sin embargo, si bien han ido emergiendo estas formas de interacción, más formalizadas y perdurables en el tiempo, estas articulaciones han carecido de espacios en que se tomen decisiones de forma horizontal. Según Fernández (2010), en un estudio exploratorio que indagó en las distintas relaciones que ocurren en los territorios, existen cuatro formas en que se desarrolla y ejecuta una articulación: (i) la articulación vertical, donde principalmente se transmite información; (ii) la articulación consultiva, a partir de la cual se desarrollan espacios de diálogo y consulta a la sociedad civil; (iii) la articulación colaborativa, donde se comparten aspectos de trabajo, como la ejecución y acción de proyectos; y (iv) la articulación territorializada, sustentada en procesos de descentralización y planificación que permiten la toma de decisiones en los propios territorios. En la región de Coquimbo prevalece más bien una articulación de tipo vertical, consultiva y colaborativa, a pesar de los esfuerzos institucionales de establecer una alianza público-privada que constituya una agenda regional de largo plazo para el desarrollo productivo.

En virtud de lo anterior, se observa que la orientación estratégica de la Corporación de Desarrollo Productivo ha sido fuertemente afectada por esta situación, cuestión que se manifiesta al prevalecer un rol difusor más que de articulador del desarrollo productivo regional. Esto implica, por lo tanto, una pérdida de influencia a nivel regional en la medida que vuelca sus esfuerzos en la administración de proyectos regionales cuyo financiamiento son frecuentemente inestables y acotados en el tiempo.

\section{Conclusiones}

Toda la renta se desvanece en el aire. Esto significa, en términos gruesos, dos grandes cosas. Por una parte, implica que el país, en un proceso histórico de largo plazo, ha construido y consolidado una estructura productiva cuya acumulación y reproducción de riqueza se basa preponderantemente en un rentismo extractivo, dependiente de los ciclos del precio de las materias primas, principalmente el cobre y, a su vez, basados en mercados altamente concentrados y orientados a la obtención de subsidios públicos. Por otra parte, expresa el hecho de que, a pesar de los esfuerzos realizados, en términos de política pública, no se han logrado desarrollar las condiciones básicas necesarias para aspirar a una transformación productiva profunda que promueva las transferencias de valor a las industrias 
más competitivas y comprometidas con el desarrollo económico, social, cultural y territorial del país.

Esto evidencia una suerte de desmodernización económica. Esta situación muestra que bajo una hegemonía rentista, se genera una ruptura entre razón instrumental, cohesión social y poder político: la economía despliega su accionar sin la necesidad de contar con mecanismos de integración social e independiente de las políticas que promueva el Estado.

El análisis de caso realizado en esta investigación, muestra que para lograr articular a los actores regionales, públicos y privados, se requiere de relaciones de confianza más robustas y comprometidas. La política pública ha asumido esta tensión, pero no ha logrado resolverla, producto de una pretensión teórica proveniente del neoinstitucionalismo, que pone el énfasis en el diseño institucional. Este enfoque, ha hecho perder la mirada sobre la construcción de subjetividad, en este caso delimitada por el territorio, en particular aquella que se levanta en el ámbito político (Lechner, 2002). Si bien se ha avanzado en el proceso de descentralización, no parece posible tener resultados importantes en términos de transformación productiva si, por un lado, no se define una orientación nacional y, por otro lado, no se profundiza en la autonomía regional, esto es, en el traspaso de decisiones fundamentales a las regiones y territorios del país. Dar este paso se enfrenta al problema fundamental de la legitimidad: desconcentrar la forma en que se funda y constituye el poder político y económico.

Como consecuencia de lo mismo, se constata, además, una diferencia de poder entre los actores que participan en el desarrollo productivo regional, lo que conduce a un desequilibrio en las condiciones iniciales, atentando contra uno de los principios de justicia promovidos, por ejemplo, por Rawls $(2009)^{14}$. Esta inestabilidad, que se genera de una situación inicial diferenciada en términos de poder económico y político, como se aprecia en la articulación público-privada regional, produce una situación de supremacía o dominación entre el que se encuentra en una posición de poder relativamente fuerte y aquel que se encuentra en una posición de poder relativamente débil (Perroux, 1961). Una consecuencia directa que se puede observar de esta situación de supremacía, es la desarticulación entre los actores del desarrollo, a raíz de esta distancia de poder, que muchas veces produce una interdependencia desigual, que se traduce en diferencias de intereses, perspectivas y lógicas sobre las cuales

\footnotetext{
${ }^{14}$ Se trata de las condiciones ideales para el diálogo social, principio de base para la construcción de legitimidad de las decisiones que allí se tomen. Cabe mencionar que no es un principio promovido solo por Rawls, sino también por toda una tradición cobijada bajo el liberalismo igualitario.
}

se funda la deseada articulación.

De esto se puede concluir, finalmente, que el problema de la transformación productiva va más allá del desencanto y desconfianza recíproca entre los ciudadanos y las instituciones políticas y sociales que promueven la articulación público-privada, como pretende el discurso actual, y radica más bien en la forma en que se despliega el sistema democrático y, por lo tanto, la gobernabilidad a partir de la cual descansa dicha relación, que a nivel regional se inscribe en una institucionalidad pública predominantemente desconcentrada y limitadamente descentralizada y autónoma, y un sistema económico fuertemente concentrado y rentista que genera desequilibrios políticos y sociales en diferentes niveles.

De esta forma, es posible concluir que las barreras que impiden el desarrollo productivo a nivel territorial se circunscriben a los ámbitos económicos, sociales y político-institucionales, cuyas características, profundidad y amplitud varían en función del territorio que se analice, aun cuando se detectan elementos comunes a lo largo del país. A juicio de los actores entrevistados, la principal barrera para avanzar hacia una efectiva transformación productiva a nivel territorial, resulta de una insuficiente y débil arquitectura institucional, que se expresa, entre otras cosas, en una falta de liderazgo de la institucionalidad pública regional para llevar adelante el proceso de desarrollo económico y la escasa articulación de los actores regionales. Por otra parte, las barreras vinculadas a la dimensión económica, se aprecian en el grado de diversificación productiva, las características de las empresas y la capacidad de generación de conocimiento que posee el territorio. En el ámbito social, se constatan barreras asociadas a las formas de construcción de subjetividad -política en este caso- y la densidad de la cohesión social y la identidad territorial. Por último, las diferencias de poder - económico y político-, la excesiva centralización del Estado y el enfoque sectorial de las políticas forman parte de las barreras que se desprenden de la dimensión político-institucional.

Por otra parte, al nivel de las políticas públicas que promueven la transformación productiva y la generación de conocimiento, existe una suerte de hegemonía de facto, al prevalecer un discurso asociado a la innovación, emprendimiento, ciencia y tecnología y capital humano pero que, en el fondo, carecen de contenido, definiciones e impacto sustantivo en esta materia. A su vez, se evidencia la falta de definición y aplicación de una política industrial que oriente la toma de decisiones en el largo plazo, asunto que, en la práctica, expresa una controversia fundamental respecto del rol del Estado como promotor del desarrollo productivo y económico del país. Las políticas de desarrollo productivo no han 
logrado impulsar la diversificación de la matriz productiva del país, lo que se expresa nítidamente en la incapacidad que han tenido para contrarrestar el proceso de desindustrialización acaecido durante las últimas décadas. Por lo tanto, se desprende de esto, que no es posible descansar solo en las políticas que promueven y fortalecen la innovación, el emprendimiento y el capital humano para la transformación productiva. Es necesario considerar, a la vez, una política industrial que se haga cargo de los desafíos de transformación productiva donde el Estado actúe de forma decidida como coordinador de este proceso.

De las regiones analizadas, no es posible corroborar la hipótesis que plantea que para implementación efectiva de políticas de desarrollo productivo o industrial y su base institucional, se requiere de una estructura productiva con mayor densidad y un capital social más robusto. Esto no quiere decir que no se haya dado el caso o que no pueda ocurrir, sino más bien que no es una condición sine qua non. Por lo tanto, un primer hallazgo en este ámbito es que no existe necesariamente una relación directa, de carácter positivo, entre diversificación productiva, capital social y articulación público-privada. Esto indica, como se ha planteado anteriormente, que hay factores político-ideológicos, económicos y sociales más profundos sobre los que se deben indagar para comprender de mejor forma este fenómeno, muchas veces paradójico.

Respecto al diseño de la política, se tiene que, por una parte, la forma que ha adquirido no ha sido capaz de articular a los actores regionales, a pesar de su vigencia, como es el caso de la región de Coquimbo. Respecto a la conformación de las Agencias o Corporaciones, se aprecia una visión meramente empresarial del desarrollo productivo en la medida que no se han incluido a representantes de trabajadores, a las pequeñas empresas, a los pueblos indígenas, organizaciones no gubernamentales vinculadas a las temáticas, los municipios, entre otros. Lo que prevalece más bien son vínculos circunstanciales destinados a resolver problemas particulares y de corto plazo mediados por proyectos con financiamiento específico que, luego de terminados los plazos, no implican necesariamente una alianza continua. Se observa una escasa pertinencia de los objetivos que han ido definiendo las agencias o corporaciones respecto de su rol en el desarrollo productivo regional.

De esta forma, se puede concluir que las alianzas público-privadas promovidas por las agencias regionales de desarrollo productivo han tenido serias dificultades para incidir en la política industrial de las regiones analizadas, por diferentes motivos. Esto, por supuesto, hay que complementarlo con el hecho de que, en rigor, no existe una política industrial a nivel nacional y menos aún a nivel regional. En efecto, al no existir una institucionalidad de carácter nacional al más alto nivel del sector público, que coordine la política industrial para el aumento de la competitividad y productividad del país, se pierde un valor estratégico esencial para la definición de este tipo de política.

\section{Recomendaciones}

Finalmente, de las conclusiones presentadas, se desprenden tres propuestas que permitirían reorientar las políticas de desarrollo productivo territorial, en los términos planteados en esta investigación.

1. Fortalecimiento de capacidades regionales:

a) Las Agencias regionales de desarrollo productivo debieran relevar y posicionar aún más su rol articulador, entendiéndose como parte de una mirada estratégica y no como un espacio para subsanar problemas específicos de los mercados regionales.

b) Las Agencias debieran incorporar en sus espacios colegiados a representantes de trabajadores, organizaciones no gubernamentales, organismos locales -como los municipios -, puesto que el desarrollo productivo es tarea de todos los actores y no solo de los empresarios.

c) Es necesario dotar de las capacidades necesarias a los gobiernos regionales, así como también realizar las modificaciones legales correspondientes para que lideren el proceso de desarrollo productivo en las regiones.

2. Generación y acumulación de conocimiento a nivel regional:

a) Es necesario impulsar una nueva concepción de la formación técnica profesional a nivel terciario. Para promover la transformación productiva se requiere de un sistema técnico que no solo se dedique a formar a los futuros profesionales sino también que contribuya al desarrollo productivo desde la innovación y la investigación aplicada. Asimismo, la oferta formativa de la educación técnica profesional debiera alinearse a una estrategia de desarrollo regional de mediano y largo plazo.

b) En este mismo sentido, se requiere conformar un sistema de educación superior 
regional equilibrado que tenga las capacidades de generación y difusión del conocimiento en sus diferentes dimensiones: básica y aplicada, así como también de transferencia. Para ello cada región debiera tener un cluster de conocimiento, liderados por las instituciones públicas en articulación con las estrategias de desarrollo y el resto de los organismos públicos presentes.

c) Para llevar adelante lo anterior se requiere aumentar de forma considerable el gasto en investigación, desarrollo e innovación $(\mathrm{I}+\mathrm{D}+\mathrm{i})$ pero direccionada con un plan de desarrollo con las instituciones públicas de educación superior.

3. Transformación productiva territorial:

a) Profundización de la descentralización del desarrollo productivo a través de una mayor autonomía regional para mejorar la legitimidad de las políticas.

b) Para mejorar la "complejidad económica" regional se debiera avanzar hacia la consideración de una producción de valor más amplia, considerando la "industria" creativa (producción y consumo cultural) como parte fundamental del desarrollo. La complejidad de una economía también radica en la capacidad de diversificación, que incluye, además de los sectores productivos tradicionales, a la cultura y las artes.

c) Se requiere considerar los efectos de las variaciones del precio del cobre en la producción minera y, por lo tanto, en la capacidad para generar empleos en el contexto del posicionamiento de esta industria como la plataforma desde la cual se piensa el desarrollo del país.

d) Es necesario optar por una política industrial selectiva para generar cluster productivos alineados con los cluster de conocimiento regional. Es decir, no basta con mejoras incrementales sobre la actual matriz productiva (las que no mejoran las capacidades para la transformación productiva), es fundamental avanzar hacia promover actividades productivas más sofisticadas, teniendo en consideración la integración regional y sus cadenas de valor.

e) Es imprescindible capturar la renta que se genera de la explotación de recursos naturales para el desarrollo de largo plazo del país, la que podrá ser destinada al desarrollo de encadenamientos tecnológi- cos y productivos relacionados (del Litio, 2015).

Por último, a partir de los puntos planteados y del análisis realizado, es posible visualizar algunas líneas de investigación que pueden resultar de interés para la política pública:

- Relación entre la dimensión económica y social del desarrollo territorial; es decir, analizar si hay vínculo entre la forma que adquiere la estructura productiva y el capital social.

- Efectos económicos y sociales de los ciclos del precio del cobre sobre los territorios del país.

- Encadenamientos productivos a nivel regional y su relación con la institucionalidad pública regional.

- Impacto de la innovación en la estructura productiva del país.

\section{Referencias}

Acquatella, J., Altomonte, H., Arroyo, A., y Lardé, J. (2013). Rentas de recursos naturales no renovables en américa latina y el caribe: evolución y participación estatal, 1990-2010.

Archer, M. S. (1996). Culture and agency. The place of culture in social theory. Cambrige University Press, New York.

Archer, M. S. (1998). Cultura y teoría social. Nueva Visión, Buenos Aires.

Archer, M. S. (2009). Teoría social realista: En enfoque morfogenético. Ediciones Universidad Alberto Hurtado, Santiago de Chile.

Arredondo, C., Inostroza, J., y Waissbluth, M. (2013). Gobiernos regionales: El eslabón perdido de la descentralización. Serie Sistemas Públicos, (8).

Bauman, Z. (2015). Modernidad líquida. Fondo de cultura económica.

Beck, U. (1998). La sociedad del riesgo: hacia una nueva modernidad. Paidós ibérica.

Boisier, S. (2007). Territorio, estado y sociedad en chile. la dialéctica de la descentralización: entre la geografía y la gobernabilidad.

CEPAL (2003). Capital social y reducción de la pobreza en América Latina y el Caribe: en busca de un nuevo paradigma. Comisión Económica para América Latina y el Caribe, Naciones Unidas y Michigan State Unviersity. 
CEPAL (2006). Australia y Nueva Zelandia: la innovación como eje de la competitividad. Comisión Económica para América Latina y el Caribe, Naciones Unidas.

CEPAL (2007). Cohesión social. Inclusión y sentido de pertenencia en América Latina y el Caribe. Comisión Económica para América Latina y el Caribe, Naciones Unidas.

CEPAL (2010). La hora de la igualdad. Brechas por cerrar, caminos por abrir. Comisión Económica para América Latina y el Caribe, Naciones Unidas.

CEPAL (2014). Cambio estructural. Una visión integrada del desarrollo. Comisión Económica para América Latina y el Caribe, Naciones Unidas.

del Litio, C. N. (2015). Informe final. Litio: una fuente de energía, una oportunidad para Chile. Ministerio de Minería, Gobierno de Chile.

Delamaza, G. (2013). Fortalecimiento de las capacidades regionales. Documento de trabajo, Series estudios territoriales, RIMISP, (9).

Devlin, R. y Moguillansky, G. (2010). Alianzas publico-privadas: para una nueva visión estratégica del desarrollo, volumen 108. United Nations Publications.

Durkheim, E. (1928). La división del trabajo social. Ediciones LEA.

Espinoza, V. (2009). Capital social y civismo en las regiones de Chile. Proyecto Desigualdades (Anillo SOC12), Subsecretaría de Desarrollo Regional y Universidad de Chile.

Fernández, M. (2010). Institucionalidad Pública desconcentrada y gobernanza territorial en Chile: desafíos para un desarrollo territorial equitativo. Programa Ciudadanía y Gestión Pública. Corporación para la Innovación en Ciudadanía Universidad de Los Lagos.

Garretón, M. A. (2004). Matriz sociopolítica y desarrollo socio-económico en Chile. Documento de trabajo.

González, R. (2012). Rol de la CORFO en el desarrollo territorial: límites de la acción institucional concertada. RIL Editores.

Habermas, J. (1987). Teoría de la acción comunicativa. Editorial Taurus.

Habermas, J. (1999). Problemas de legitimación en el capitalismo tardío. Amorrortu.

Ibáñez, J. (2003). Más allá de la sociología. El grupo de discusión: técnica y crítica. Siglo XXI, Madrid.
Jean-François, L. (2004). La condición postmoderna. Cátedra.

Katz, J. (2008). Una nueva visita a la teoría del desarrollo económico. Comisión Económica para América Latina y el Caribe, Naciones Unidas.

Lechner, N. (2002). Las sombras del mañana: la dimensión subjetiva de la política. LOM ediciones.

Moguillansky, G. (2010). Las agencias regionales de desarrollo productivo: un germen de colaboración público-privada para el desarrollo regional en chile.

Moguillansky, G. (2012). Comisiones y consejos nacionales de competitividad: Aunando los intereses público y privado en colombia y república dominicana. Technical report, Inter-American Development Bank.

Moguillansky, G., Ramírez, E., y Furnaro, A. (2013). Las políticas de desarrollo productivo en chile 1990 y 2012. Documento de trabajo, Series estudios territoriales, RIMISP, (19).

Moncayo, E. (2001). Evolución de los paradigmas y modelos interpretativos del desarrollo territorial. ILPES-CEPAL.

Muñoz, O., editor (2009). Desarrollo Productivo en Chile: La Experiencia de Corfo entre 1990 y 2009. CORFO, FLACSO Chile, Catalonia.

Navarro, P. y Díaz, C. (1995). Análisis de Contenido. Síntesis.

North, D. C. (1981). Estructura y cambio en la historia económica. Alianza, Madrid.

North, D. C. (1990). Institutions, Institutional Change and Economic Performancea. Cambridge University Press, New York.

OCDE (2009). Estudios territoriales. Chile. Organización para la Cooperación y el Desarrollo Económico.

Peña, C. (2008). El concepto de cohesión social. Debates teóricos y usos políticos. Uqbar Editores.

Perroux, F. (1961). La economía del siglo $X X$. Ariel.

PNUD (2015). Informe desarrollo humano en chile 2015: Los tiempos de la politización.

Putnam, R. D., Feldstein, L. M., y Cohen, D. (2003). Better together. Simon \& Schuster.

Putnam, R. D., Leonardi, R., y Nanetti, R. Y. (1994). Making democracy work: Civic traditions in modern Italy. Princeton university press. 
Rawls, J. (2009). A theory of justice. Harvard university press.

Riesco, M. (2012). La gran pregunta.

Riesco, M. (2014a). ¿es chile un país capitalista?

Riesco, M. (2014b). Vacas flacas.

Rodríguez, P. y Román, C. (2005). El capital social como factor de competitividad y desarrollo empresarial. Ekonomiaz: Revista vasca de economía, (59):214-231.

Sen, A. (2000). Libertad y desarrollo. Editorial Planeta.

SUBDERE (2011). Masa crítica de condiciones para el desarrollo de las regiones. Antecedentes para una discusión incipiente. Subsecretaría de Desarrollo Regional y Administrativo, Gobierno de Chile.

SUBDERE (2013). Diagnóstico preliminar de las corporaciones regionales de desarrollo producti- vo. Documento de trabajo interno División de Políticas y Estudios, Subsecretaría de Desarrollo Regional y Administrativo, Gobierno de Chile.

SUBDERE (2014). Gobiernos regionales y universidades. Una institucionalidad para el desarrollo. Documento de trabajo interno División de Políticas y Estudios, Subsecretaría de Desarrollo Regional y Administrativo, Gobierno de Chile.

SUBDERE-UFRO (2012). Más talentos para el desarrollo regional. Propuestas para la construcción de una política de Estado de capital humano calificado para el desarrollo equilibrado de Chile. Subsecretaría de Desarrollo Regional y Administrativo, Gobierno de Chile y Universidad de la Frontera.

Touraine, A. (1999). ¿Podremos vivir juntos?: iguales y diferentes. Fondo de Cultura Económica. 